\title{
STRATEGI PENGEMBANGAN USAHA TANI TOMAT DALAM UPAYA MENEMBUS SINGAPURA (STUDI KASUS MITRA TANI PARAHYANGAN)
}

\author{
STRATEGY OF TOMATO BUSINESS DEVELOPMENT IN PENETRATING THE SINGAPORE MARKET \\ (CASE STUDY OF TANI PARAHYANGAN PARTNER)
}

\author{
Ibrahim Chalid Siregar ${ }^{* 1}$, Mukhamad Najib ${ }^{* *}$, dan Ono Suparno***) \\ *) Sekolah Bisnis, Institut Pertanian Bogor \\ Jl. Raya Pajajaran, Bogor 16151 \\ ${ }^{* *}$ Departemen Manajemen, Fakultas Ekonomi dan Manajemen, Institut Pertanian Bogor \\ Jl. Agatis Kampus IPB, Darmaga, Bogor 16680 \\ ${ }^{* * *}$ Departemen Teknologi Industri Pertanian, Fakultas Teknologi Pertanian, Institut Pertanian Bogor \\ Gedung Fateta Lantai 2, Kampus IPB Dramaga, Bogor 16680
}

\begin{abstract}
The objectives of this study were 1) to identify strengths, weaknesses, opportunities and threats of the Mitra Tani Parahyangan (MTP) in its efforts to expand its export market, 2) to formulate strategies that could be utilized by MTP, 3) to prioritize the strategies that could be applied by MTP. Methodology employed included internal and external analysis and industrial analysis, SWOT matrices, followed by determination of decision priority using Analytical Hierarchy Process (AHP). Based on the result of external environment analysis, there were five opportunity factors and seven threat factors which became the strategic issues. Meanwhile, according to the result of internal environment analysis, there were four strength factors and five weakness factors which became the strategic issues. The result of EFE matrix showed that the company's ability to respond to external factors was reasonably good in harnessing opportunities and avoiding threats. On the other hand, the result of IFE matrix showed that the company's current internal position is weak. Through the matching of strategic issues within the internal and external environment, and seven alternative strategy formulations that can be applied by the company were generated. Collaborating with domestic forwarder agents is an alternative priority strategy chosen through AHP analysis tools.
\end{abstract}

Keywords: AHP, SWOT, Tomato, OVOP

Abstrak: Tujuan dari penelitian ini adalah 1) mengidentifikasi kekuatan, kelemahan, peluang, dan ancaman Mitra Tani Parahyangan (MTP) dalam upaya mengembangkan ekspansi pasar ekspor, 2) memformulasikan strategi-strategi yang dapat dijalankan oleh MTP, 3) menentukan prioritas strategi yang dapat dijalankan oleh MTP. Metode penelitian ini menggunakan analisis internal eksternal dan analisis industri, matriks SWOT, dan pengambilan keputusan dengan Analytical Hierarchy Process (AHP). Berdasarkan hasil analisis lingkungan eksternal didapati lima faktor peluang dan tujuh ancaman yang merupakan isu strategis. Pada lingkungan internal didapati empat faktor kekuatan dan lima kelemahan yang merupakan isu strategis. Hasil matriks EFE menunjukkan kemampuan perusahaan dalam mersepon faktor eksternal yang cukup baik dalam memanfaatkan peluang dan menghindari ancaman. Sedangkan pada hasil analisis matriks IFE menunjukkan bahwa posisi internal perusahaan saat ini lemah. Melalui pencocokan isu-isu strategis yang terdapat pada lingkungan internal dan eksternal perusahaan, dihasilkan tujuh rumusan alternatif strategi yang dapat dijalankan perusahaan. Menjalin kerjasama dengan agen forwarder dalam negeri merupakan prioritas alternatif strategi yang terpilih melalui alat analisis AHP.

Kata kunci: AHP, SWOT, Tomat, OVOP

\footnotetext{
${ }^{1}$ Corresponding author:

Email: ibrahim.csiregar@gmail.com
} 


\section{PENDAHULUAN}

Salah satu subsektor pertanian yang memiliki peranan penting dalam menunjang pembangunan dan perekonomian nasional adalah subsektor hortikultura. Hortikultura merupakan subsektor yang layak untuk dijadikan salah satu prioritas dalam pengembangan pertanian karena memiliki nilai komersil yang cukup tinggi dan berkonstribusi besar terhadap pemenuhan kebutuhan gizi berbagai lapisan masyarakat baik di dalam maupun luar negeri. Hal ini didukung oleh karakteristik lahan dan agroklimat serta sebaran wilayah yang luas memungkinkan wilayah Indonesia sebagai daerah yang sangat berpotensial untuk mengembangkan komoditas hortikultura.

Salah satu komoditas hortikultura dalam negeri yang dikategorikan unggulan berdasarkan nilai ekonomis dan strategis menurut Direktorat Jendral Hortikultura adalah tomat. Tomat memiliki potensi yang sangat tinggi untuk dibudidayakan di Indonesia. Tergantung jenis atau varietasnya, tanaman ini dapat ditanam secara leluasa dari mulai dataran rendah sampai dataran tinggi. Tidak hanya untuk konsumsi langsung, perkembangan pemanfaatan tomat sebagai produk olahan pun semakin meningkat penggunaannya baik untuk baku produk makanan olahan hingga produk kecantikan.Turut didukung oleh penelitian yang dilakukan Kusuma dan Firdaus (2015), tomat indonesia memiliki keunggulan komparatif dan kompetitif dalam persaingan pasar ekspor.

Selama lima tahun terakhir (2008-2012) rata-rata produksi tomat Indonesia berdasarkan Kementan (2014) berada di urutan pertama di ASEAN dengan kontribusi $66,82 \%$ atau rata-rata produksi 863.632 ton. Negaranegara lainnya yang memberikan kontribusi produksi tomat di ASEAN adalah Filipina 15,57\% (201.238 ton) dan Thailand $10,54 \%$ (136.211 ton), dan Negara lainnya sebesar 7,08\% (91.462 ton). Namun sangat disayangkan proporsi ekspor Indonesia di wilayah ASEAN masih tertinggal jauh dengan Malaysia yang memiliki proporsi kontribusi ekspor pada wilayah ASEAN sebesar $94,54 \%$ atau 28.884 ton dan Indonesia hanya berkontribusi sebesar 3,05\% atau 917 ton.

Mitra Tani Parahyangan (MTP) merupakan perusahaan yang bergerak di bidang budidaya dan pemasaran hortikultura-sayuran. Hingga tahun 2016 total komoditas yang dipasarkan oleh MTP terdiri dari 150 jenis sayuran daun dan sayuran buah. Salah satu produk unggulan yang berhasil dikembangkan oleh MTP yang memiliki kualitas dan daya saing tinggi adalah Tomat One Village One Product (OVOP). One Village One Product (OVOP) merupakan suatu label dan program upaya yang dilakukan pemerintah dalam rangka peningkatan efektifitas dalam rangka mengembangkan Industri Kecil dan Menengah (IKM). Beberapa tujuan pengembangan OVOP adalah 1) menggali dan mempromosikan produk inovatif dan kreasi lokal yang bersifat unik khas daerah; 2) meningkatkan jumlah produk IKM yang bernilai tambah tinggi yang berdaya saing global (Kemenperin, 2017).

Keinginan MTP untuk mengekspor produk tomat berawal dari kemampuan perusahaan dalam pengadaan tomat berkualitas yang berjumlah 2-3 ton tiap harinya. Namun, sangat disayangkan dari segi pemasaran MTP selama ini hanya mampu menyalurkan sebesar 1-2 ton per hari. Pertimbangan lainnya adalah MTP menganggap bahwa terdapat prospek bisnis dari kegiatan ekspor tomat. Dari sisi impor, Singapura menempati urutan pertama sebagai negara importir tomat terbesar di ASEAN dengan rata-rata volume impor sebesar 29.115 ton atau berkontribusi $88,20 \%$ terhadap volume impor tomat ASEAN. Urutan berikutnya yaitu Malaysia (9,42\%), Thailand (1,08\%), Filipina $(0,58 \%)$, Brunei Darussalam $(0,43 \%)$, Indonesia ( $0,29 \%$, setara dengan 94 ton) (Kementan 2014). Melalui kegiatan ekspor MTP berharap dapat menyalurkan kapasitas produksinya secara optimal sehingga dapat meningkatkan pendapatan perusahaan dan mitra sehingga dapat membantu perbaikan taraf hidup para petani mitra.

Penelitian ini bertujuan 1) mengidentifikasi kekuatan, kelemahan, peluang, dan ancaman MTP dalam upaya mengembangkan ekspansi pasar ekspor, 2) memformulasikan strategi-strategi yang dapat dijalankan oleh MTP, 3) menentukan prioritas strategi yang dapat dijalankan oleh MTP. Penelitian ini dilakukan di Mitra Tani Parahyangan yang berlokasi di Kabupaten Cianjur, Jawa Barat Pasar ekspor yang dituju adalah Singapura sehingga lingkungan eksternal yang digunakan hanya akan membahas terkait dengan iklim bisnis (peluang dan ancaman) di Singapura dan Indonesia.

Kebaharuan dalam penelitian ini adalah pada subyek penelitian, yaitupada perusahaan agribisnis buah. Belum begitu banyak penelitian terdahulu yang membahas tentang ekspor buah, terutama buah tomat OVOP yang 
memiliki pangsa pasar potensial di luar negeri. Telah ada penelitian sebelumnya dari Syachbanu (2014) yang meneliti tentang penanganan kargo pada komoditas hortikultura ekspor, tetapi penelitian Syachbanu memiliki lingkup berupa proses penanganan dan risiko ekspor dan tidak membuat formulasi strategi untuk menembus pasar ekspor. Penelitian ini melakukan beberapa analisis seperti analisis internal-eksternal, merumuskan strategi alternatif, dan terakhir memilih strategi prioritas.

\section{METODE PENELITIAN}

Penelitian ini dilaksanakan pada Bulan September 2016 sampai dengan Desember 2017. Lokasi penelitian berada di Mitra Tani Parahyangan Cianjur yang beralamat di Kabupaten Cianjur, Jawa Barat. Data yang digunakan dalam penelitian ini adalah data primer dan data sekunder. Data primer adalah data yang diperoleh atau dikumpulkan melalui analisis lingkungan internal. Data primer diperoleh melalui observasi dan wawancara menggunakan bantuan kuesioner. Data sekunder merupakan data yang dikumpulkan dari sumber lain yang sudah siap untuk diolah. Data sekunder yang digunakan adalah data yang berasal dari internal MTP dan dari penelitian-penelitian terdahulu.

Pengambilan data dalam penelitian dilakukan dengan menggunakan metode observasi, wawancara, dan pemberian kusioner. Metode observasi digunakan untuk mengamati proses bisnis, kondisi sumber daya manusia serta kegiatan yang berhubungan dengan kelangsungan usaha. Metode wawancara digunakan untuk menggali informasi berkaitan dengan gagasan, ide, perasaan dan pikiran nara sumber sesuai dengan tujuan penelitian. Sementara kuesioner dibutuhkan untuk memperoleh informasi mengenai faktor strategis dan prioritas strategi yang dapat dijalankan perusahaan dalam upaya melakukan pengembangan. Responden dipilih merupakan seorang ahli atau kompeten di bidang yang akan dikaji dan memiliki andil dalam objek yang akan diteliti. Jumlah sampel untuk kegiatan wawancara adalah menyesuaikan kondisi di lapangan yaitu dengan teknik purposive sampling. Responden dipilih sebanyak tujuh orang dengan pertimbangan bahwa responden tersebut merupakan seorang ahli atau kompeten di bidang yang akan dikaji dan memiliki andil dalam objek yang akan diteliti.
Berikut ini merupakan teknik analisis data yang digunakan dalam penelitian: 1) Analisis Eksternal (analisis lingkungan eksternal yang dilakukan pada penelitian ini adalah Lingkungan jauh yang meliputi aspek politik, ekonomi, sosial budaya, dan teknologi; Lingkungan Indsutri yang meliputi ancaman pendatang baru, persaingan sesama perusahaan sejenis, kekuatan tawar menawar pemasok, kekuatan tawar menawar pembeli, dan produk pengganti); 2) Analisis Internal (analisis lingkungan internal dilakukan pada bidangbidang yang meliputi sistem manajemen, pemasaran, keuangan/akuntansi, produksi/operasi, serta penelitian dan pengembangan); 3) Analisis SWOT (alternatif strategi hasil kombinasi faktor internal-eksternal dirumuskan dalam matriks SWOT, terdiri dari strategi SO (strengths-opportunities), WO (weaknessesoppoertunities), ST (strengths-threats) dan WT (weaknesses-threats) (Rangkuti, 2015)); 4) Analytical Hierarchy Process (AHP) (langkah-langkah yang dilakukan dalam upaya pemecahan persoalan adalah (Bhusnandan Rai, 2004): penyusunanhierarki; penilaian level hierarki dengan perbandingan berpasangan menggunakan skala 1-9; penentua prioritas; dan 4) penilaian konsistensi logis). Kerangka pemikiran penelitian selengkapnya pada Gambar 1.

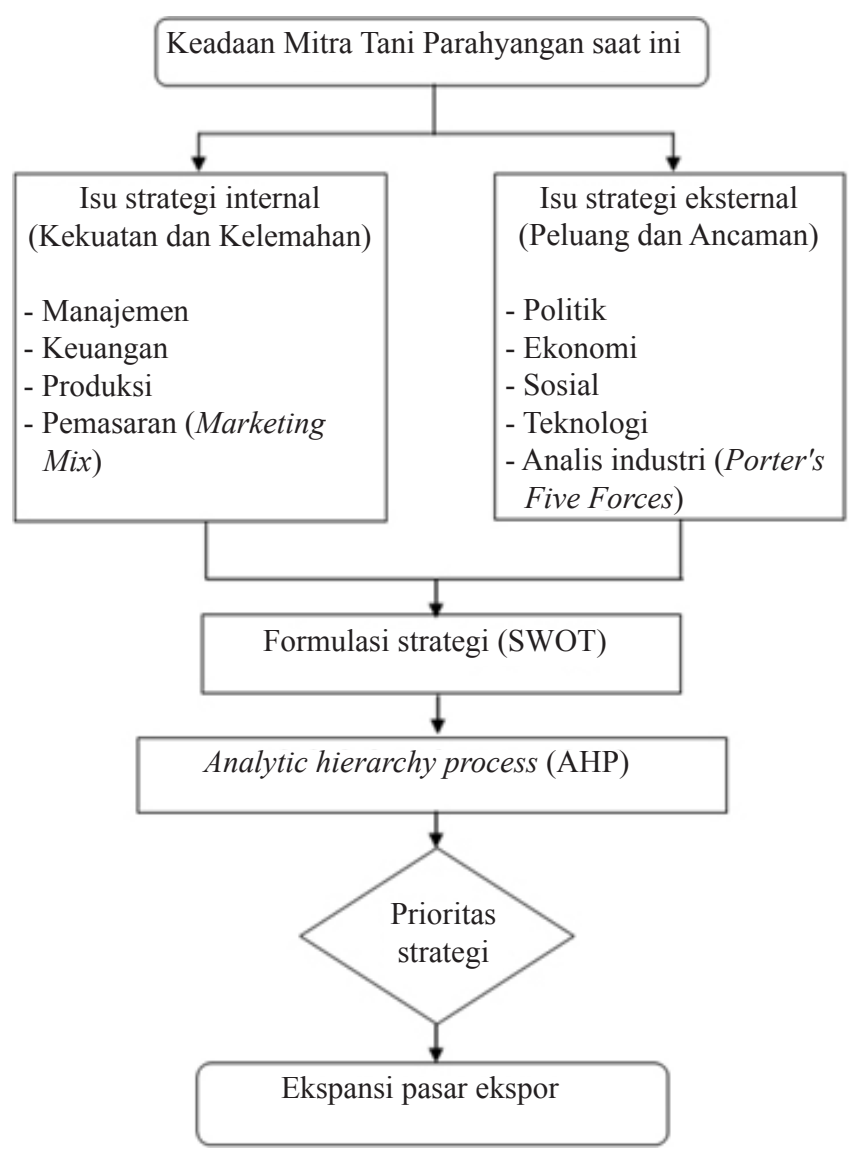

Gambar 1. Kerangka pemikiran penelitian 


\section{HASIL}

Mitra Tani Parahyangan (MTP) merupakan suatu perusahaan produsen dan distributor yang bergerak di bidang usaha tanaman pangan dan hortikultura khususnya sayuran. Perusahaan ini beralamat di Kampung Padakati RT 04/RW 01 Desa Tegallega Kecamatan Warung Kondang Cianjur Jawa Barat sebagai gudang pusat dan JL. KH Abdullah Bin Nuh Pesona Indah Cluster Blok B No 11-12 yang merupakan kantor pusat. Komoditas yang tersedia dan ditawarkan MTP berjumlah 140 jenis komoditas, baik dari tanaman pangan, obat, dan buah-buahan. Selain memproduksi sendiri, komoditas yang dipasok oleh MTP berasal dari kemitraan kelompok petani yang beranggotakan 30 orang. Perusahaan ini menjalankan usahanya dengan sistem intiplasma dimana Mitra Tani Parahyangan sebagai pusatnya yang diorganisir oleh Bapak Ujang Majudin.

\section{Analisis Lingkungan Internal dan Eksternal}

Hasil analisis matriks EFE memiliki nilai total skor sebesar 2,758 (Tabel 1). Nilai tersebut menunjukkan kemampuan perusahaan dalam mersepon faktor eksternal yang cukup baik di atas nilai rata-rata $(2,5)$ dalam memanfaatkan peluang dan menghindari anacaman. Banyaknya akses distribusi untuk ekspor di dalam negeri merupakan peluang utama dengan nilai skor terbesar, yaitu 0,300.Ketersediaan jasa forwarder dalam negeri yang banyak turut menunjang peluang yang dapat dimanfaatkan MTP dalam memberikan pertimbangan peta jalur distribusi, gambaran biaya, hingga pengurusan segala kubutuhan dokumen yang dibutuhkan (Sibarani dan Ispriyahadi, 2004; Hill et al. 2014).Sementara itu, kondisi cuaca yang tidak menentu menjadi ancaman utama dengan nilai skor sebesar 0,337. Faktor tersebut memiliki pengaruh yang besar terhadap jumlah hasil output komoditas dan kualitas yang dihasilkan.

Hasil analisis matriks IFE MTP memiliki total skor internal sebesar 2,379 (Tabel 2) yang menunjukkan bahwa posisi internal perusahaan saat ini lemah. Kekuatan utama sebagai pendukung keberhasilan pengembangan MTP adalah faktor Sudah menerapkan GAP, GHP, dan GMP dalam proses produksi dengan nilai skor sebesar 0,516. Beberapa penelitian menunjukkan petani yang menerapkan GAP dalam sistem produksinya dapat menghasilkan output produksi dan pemasukan yang lebih besar dibandingkan dengan yang tidak menerapkan GAP (Islam et al. 2012; Schreinemachers et al. 2012).

Tabel 1. Hasil analisis matriks EFE pengembangan MTP dalam upaya menembus pasar ekspor

\begin{tabular}{lccc}
\hline Faktor Strategis Eksternal & Bobot & Nilai & Skor \\
\hline Peluang & & & \\
Singapura memiliki pendapatan per kapita yang tinggi & 0,074 & 2,6 & 0,192 \\
Banyaknya akses distribusi untuk ekspor di dalam negeri & 0,091 & 3,3 & 0,300 \\
Gaya hidup sehat masyarakat Singapura tinggi & 0,077 & 2,6 & 0,200 \\
Aksesibilitas informasi melalui internet yang semakin mudah dan interaktif & 0,072 & 2,9 & 0,209 \\
Kekuatan tawar menawar pemasok yang lemah & 0,076 & 2,3 & 0,175 \\
Ancaman & & & \\
Kondisi cuaca yang tidak menentu & 0,099 & 3,4 & 0,337 \\
Sertifikasi kesehatan tumbuhan Indonesia & 0,096 & 3,3 & 0,317 \\
Harga tomat dalam negeri yang cenderung berfluktuatif & 0,088 & 2,4 & 0,211 \\
Ancaman pendatang baru tinggi & 0,072 & 2,3 & 0,166 \\
Ancaman produk pengganti tinggi. & 0,083 & 2,6 & 0,216 \\
Kekuatan tawar menawar pembeli yang kuat & 0,087 & 2,1 & 0,183 \\
Tingginya persaingan perusahaan di Singapura & 0,084 & 3,0 & 0,252 \\
\hline TOTAL & & & 2,758 \\
\hline
\end{tabular}


Tabel 2. Hasil analisis matriks IFE pengembangan MTP dalam upaya menembus pasar ekspor

\begin{tabular}{lccc}
\hline Faktor Strategis internal & Bobot & Nilai & Skor \\
\hline Kekuatan & & & \\
Citra public dalam negeri yang baik & 0,098 & 3,1 & 0,304 \\
Sudah menerapkan GAP, GHP, dan GMP dalam proses produksi & 0,129 & 4,0 & 0,516 \\
Produk tersertifikasi OVOP & 0,113 & 3,6 & 0,407 \\
Lokasi gudang yang strategis dan ketersediaan sarana transportasi yang memadai & 0,101 & 3,6 & 0,364 \\
Kelemahan & & & \\
Belum memiliki kontrak kerjasama yang tertulis dengan mitra & 0,107 & 1,1 & 0,118 \\
Frekuensi penggunaan obat berbahan kimia yang cukup tinggi & 0,115 & 1,6 & 0,184 \\
Kepemilikan lahan yang berbentuk sewa & 0,095 & 1,7 & 0,162 \\
Fasilitas dan sarana pascapanen yang kurang memadai & 0,118 & 1,6 & 0,189 \\
Belum memiliki mitra dagang ekspor & 0,123 & 1,1 & 0,135 \\
\hline Total & & & 2,379 \\
\hline
\end{tabular}

Di sisi lain, hal yang menjadi kelemahan utama adalah faktor Belum memiliki kontrak kerja sama yang tertulis dengan mitra dengan nilai skor 0,118 . Beberapa dampak yang terjadi dari faktor tersebut adalah terkadang mitra menjual langsung kepada konsumen lain atau kepada perusahaan lain ketika harga naik, dan proporsi tomat grade $\mathrm{B}$ dan $\mathrm{C}$ yang terkadang masih didapati berjumlah cukup besar. Hal ini akan berpengaruh terhadap keberlangsungan usaha MTP ke depannya, terutama apabila MTP telah berhasil memasarkan produknya ke luar negeri dimana dibutuhkan keseragaman kualitas dengan kuantitas yang besar.

\section{Formulasi Strategi Menggunakan Matriks SWOT}

Formulasi strategi pengembangan MTP dalam upaya menembus pasar ekspor terdapat pada Gambar 2. Hasil analisis SWOT yang ditunjukkan pada Gambar 2 membentuk tujuh strategi alternatif.

1) Strategi (SO) Memanfaatkan E-commerce sebagai media promosi perusahaan. Salah satu tantangan utama dalam bisnis ekpor adalah jarak tempuh yang jauh. Hal tersebut sangat memengaruhi suatu perusahaan dalam mencari informasi dan menjalin suatu kerja sama. Adopsi teknologi menjadi hal yang harus dilakukan dapat memberikan kemampuan bagi suatu usaha untuk memberikan layanan yang semakin baik dan daya saing (Apulu dan Latham, 2011). Hal ini selaras dengan yang diungkapkan Muafi et al. (2010) keberhasilan untuk mempopulerkan produk unggulan (OVOP) dapat dicapai dengan penguasaan praktik bisnis berbasis teknologi informasi. Mengingat sasaran pasar produk unggulan adalah ke luar negeri, maka penggunaan mediasi khususnya E-commerce sangat dibutuhkan (Asikin, 2016).

2) Strategi (ST1) Membuat sertifikasi HACCP. Masyarakat Singapura yang merupakan target pengembangan pemasaran MTP memiliki gaya hidup sehat yang tinggi. Hal tersebut berdampak pada tingginya tuntutan akan makanan yang aman untuk dikonsumsi dan dan lingkungan yang bebas dari hama dan penyakit. Konsumen menginginkan adanya jaminan bahwa makanan yang diimpor telah lolos standar kesehatan dan keamanan yang berlaku (Thaung, 2011). Salah satu strategi dalam upaya memenuhi ekspektasi tersebut adalah dengan dilakukannya sertifikasi HACCP (Hazard Analysis and Critical Control Point).

3) Strategi (ST2) Membuat suatu kemasan produk yang memiliki nilai budaya lokal dan OVOP. Upaya MTP dalam mengembangkan pemasarannya menuju pasar internasional senantiasa sarat akan persaingan. MTP dapat menerapkan ide Suharto (2000), dimana desain kemasan dapat dijadikan sebagai salah satu alat pemasaran. Kemasan tidak hanya berfungsi sebagai pelindung, tetapi kini kemasan digunakan sebagi media komunikasi antara konsumen dengan produsen (Kumar et al. 2017). Kemasan merupakan pemicu karena langsung berhadapan dengan konsumen. Karena itu kemasan harus dapat memengaruhi konsumen untuk memberikan respon positif, dalam hal ini membeli produk; karena tujuan akhir dari pengemasan adalah untuk menciptakan penjualan. 
4) Strategi (WO1) Pembelian lahan produksi dengan status kepemilikan. Menurut Suratiyah (2006) status kepemilikan dapat dibagi menjadi tiga, yaitu hak milik, hak sewa, dan hak bagi hasil. Perbedaan hubungan tersebut akan memengaruhi kesediaan petani dalam meningkatkan produksi, memperbaiki kesuburan tanah, dan intensifikasi. Kusnadi et al. (2011) menyatakan status lahan kepemilikan akan menurunkan inefisiensi dibandingkan status lahan nonpemilik, atau dengan kata lain kepemilikan lahan akan meningkatkan efisiensi usahatani. Hal ini terjadi karena dengan kepemilikan lahan yang digarap, terdapat sense of belonging sehingga petani akan memanfaatkan lahan tersebut sebaik-baiknya dan menghasilkan efisiensi yang lebih tinggi hingga akhrinya tercipta sebuah keunggulan kompetitif.

5) Strategi (WO2) Menerapakan sistem pertanian semi organik. Salah satu strategi MTP dalam upaya meningkatkan daya saingnya adalah dengan menerapkan sistem pertanian semi organik. Kualitas dan harga suatu komoditas semi organik tidaklah berbeda jauh dengan komoditas organik (Kipdiyah et al. 2013). Di samping itu, pertanian semi organik merupakan suatu langkah awal dalam proses adopsi ke sistem pertanian organik. Hal ini karena perubahan yang ekstrim dari pola pertanian yang biasa diterapkan suatu perusahaan yang mengandalkan pupuk kimia, menjadi pola pertanian organik yang mengandalkan pupuk biomasa akan berakibat langsung terhadap penurunan hasil produksi yang cukup signifikan (Sutanto, 2002).

6) Strategi (WO3) Menjalin kerja sama dengan agen forwarder dalam negeri. Proses forwarding yang panjang dan kompleks membuat perusahaan yang berniat melakukan ekspor menggunakan jasa freight forwarder. Freigth forwarder adalah suatu badan usaha spesialis perdagangan yang memiliki keahlian dalam menyediakan bermacam-macam fungsi dan fasilitas untuk transportasi barang (Murphy dan Daley, 2001). Beberapa forwarder bahkan tidak hanya menangani dokumen-dokumen, konsultasi jalur pengiriman, dan merumuskan biaya, mereka juga menawarkan jasa bersamaan dengan asuransi pengiriman dan rekomendasi metode pengemasan

7) Strategi (WT) Meningkatkan standar penanganan pasca panen. Komoditas yang dipedangangkan oleh MTP adalah komoditas agribisnis yang memiliki sifat perishable yang apabila selesai dipanen tidak ditangani dengan baik maka akan segera rusak. Panjangnya rantai pasok dalam distribusi komoditas dan tuntutan kualitas baik dari dalam negeri maupun pasar yang dituju memerlukan suatu perhatian khusus agar perusahaan dapat berhasil memasarkan produknya dengan mutu yang senantiasa terjaga.

\begin{tabular}{|c|c|c|}
\hline & $\begin{array}{l}\text { (S) Strengths - Kekuatan: } \\
\text { 1. Citra publik dalam negeri yang baik } \\
\text { 2. Sudah menerapkan GAP, GHP, dan } \\
\text { GMP dalam proses produksi } \\
\text { 3. Produk tersertifikasi OVOP } \\
\text { 4. Lokasi gudang yang strategis dan } \\
\text { ketersediaan sarana transportasi } \\
\text { yang memadai }\end{array}$ & $\begin{array}{l}\text { (W) Weakness - Kelemahan: } \\
\text { 1. Belum memiliki kontrak kerja sama } \\
\text { yang tertulis dengan mitra } \\
\text { 2. Frekuensi penggunaan obat berbahan } \\
\text { kimia yang cukup tinggi } \\
\text { 3. Kepemilikan lahan yang berbentuk } \\
\text { sewa } \\
\text { 4. Fasilitas dan sarana pascapanen yang } \\
\text { kurang memadai } \\
\text { 5. Belum memiliki mitra dagang ekspor }\end{array}$ \\
\hline $\begin{array}{l}\text { (O) Opportunities - Peluang: } \\
\text { 1. Singapura memiliki pendapatan per kapita yang } \\
\text { tinggi } \\
\text { 2. Ketersedian akses distribusi untuk ekspor dalam } \\
\text { negeri banyak } \\
\text { 3. Gaya hidup sehat masyarakat Singapura tinggi } \\
\text { 4. Aksesibilitas informasi melalui internet yang } \\
\text { semakin mudah dan interaktif } \\
\text { 5. Kekuatan tawar menawar pemasok yang lemah }\end{array}$ & $\begin{array}{l}\text { Strategi SO } \\
\text { 1. Memanfaatkan E-commerce sebagai } \\
\text { media promosi perusahaan. (S1, S2, } \\
\mathrm{S} 3, \mathrm{~S} 4, \mathrm{~S} 5, \mathrm{O} 1, \mathrm{O} 2, \mathrm{O} 3, \mathrm{O} 4, \mathrm{O} 5)\end{array}$ & $\begin{array}{l}\text { Strategi WO } \\
\text { 1. Pembelian lahan produksi dengan } \\
\text { status kepemilikan (W2, W3, W5, O1, } \\
\text { O2, O3) } \\
\text { 2. Menerapkan sistem pertanian semi } \\
\text { organik. (W1, W2, W3, W4, O1, O3, } \\
\text { O4,) } \\
\text { 3. Menjalin kerjasama dengan agen } \\
\text { forwarder dalam negeri (W4, W5, O1, } \\
\text { O2, O3, O4, O5) }\end{array}$ \\
\hline $\begin{array}{l}\text { (T) Threats-Ancaman: } \\
\text { 1. Kondisi cuaca yang tidak menentu } \\
\text { 2. Sertifikasi kesehatan tumbuhan Indonesia } \\
\text { 3. Harga tomat dalam negeri yang cenderung } \\
\text { berfluktuatif } \\
\text { 4. Ancaman pendatang baru tinggi } \\
\text { 5. Ancaman produk pengganti tinggi } \\
\text { 6. Kekuatan tawar menawar pembeli yang kuat } \\
\text { 7. Tingginya persaingan perusahaan di Singapura }\end{array}$ & $\begin{array}{l}\text { Strategi ST } \\
\text { 1. Membuat sertifikasi HACCP (S1, } \\
\text { S2, ,S3, S4, S5, T2, T3, T4, T5, T6, } \\
\text { T7) } \\
\text { 2. Membuat suatu kemasan produk } \\
\text { yang memiliki nilai budaya lokal } \\
\text { dan OVOP (S1, S2, S3, S4, T3, T4, } \\
\text { T5, T6, T7) }\end{array}$ & $\begin{array}{l}\text { Strategi WT } \\
\text { 1. Meningkatkanstandar penanganan } \\
\text { pasca panen. (W1, W2, W4, W5, T1, } \\
\text { T2, T3, T4, T5, T6, T7) }\end{array}$ \\
\hline
\end{tabular}

Gambar 2. Matriks SWOT dan alternatif-alternatif strategi 


\section{Pemilihan Prioritas Strategi Menggunakan AHP}

Skema Hierarki pengolahan strategi ekspor MTP ditunjukkan pada Gambar 3. Hasil analisis dan prioritas setiap unsur Hierarki tersaji pada Tabel 3. Faktor kualitas merupakan unsur faktor yang paling berpengaruh terhadap sasaran utama dengan skor $(0,338)$. Konsumen internasional khususnya dari negara maju seperti Singapura, menginginkan produk bermutu dengan tampilan yang bagus disertai dengan terjaminnya keamanan konsumsi, seperti bebas pestisida, hama, dan lain-lain (Miyauchi dan Perry, 1999; Chomchalow et al. 2008; Chomchalow et al. 2008; Srimanee dan Routray, 2012; Sutrisno et al. 2013; Purnama, 2014).

MTP merupakan aktor yang paling berpengaruh terhadap sasaran utama (skor 0,367). MTP sebagai poros utama memiliki peranan dan tanggung jawab yang besar dalam menghasilkan mutu yange baik dan memastikan kelancaran pada setiap alur proses barang. Pengembangan pasar merupakan tujuan yang menjadi prioritas utama dalam upaya menembus pasar ekspor dengan skor 0,396.Tingginya tingkat persaingan di dalam negeri merupakan pertimbangan dasar bagi MTP untuk meningkatkan daya saing perusahaan dan melebarkan pangsa pasarnya ke luar negeri.Hal ini dilakukan dengan harapan hasil produksi dapat senantiasa tersalurkan.

Menjalin kerja sama dengan agen forwarder dalam negeri merupakan strategi prioritas pertama (skor $0,215)$.Hal ini disinyalir karena minimnya pengalaman MTP dalam dunia ekspor impor sehingga menjalin kerja sama dengan freight forwarder merupakan langkah yang paling tepat pada saat ini.Umumnya forwarder diketahui sebagai kunci perantara yang terlibat dalam transportasi barang (cargo) dari titik asal (origin) ke titik tujuan (destination) melalui laut maupun udara. Namun di sisi lain, forwarder juga menyediakan jasa pelayanan konsultasi berkenaan dengan kebutuhan informasi dalam berbagai aspek, seperti kondisi negara tujuan, informasi kebutuhan atau permintaan pasar luar negeri, dan relasi perusahaan atau end consumer yang dapat dijadikan sasaran pemasaran MTP (Murphy et al.2001).

Faktor

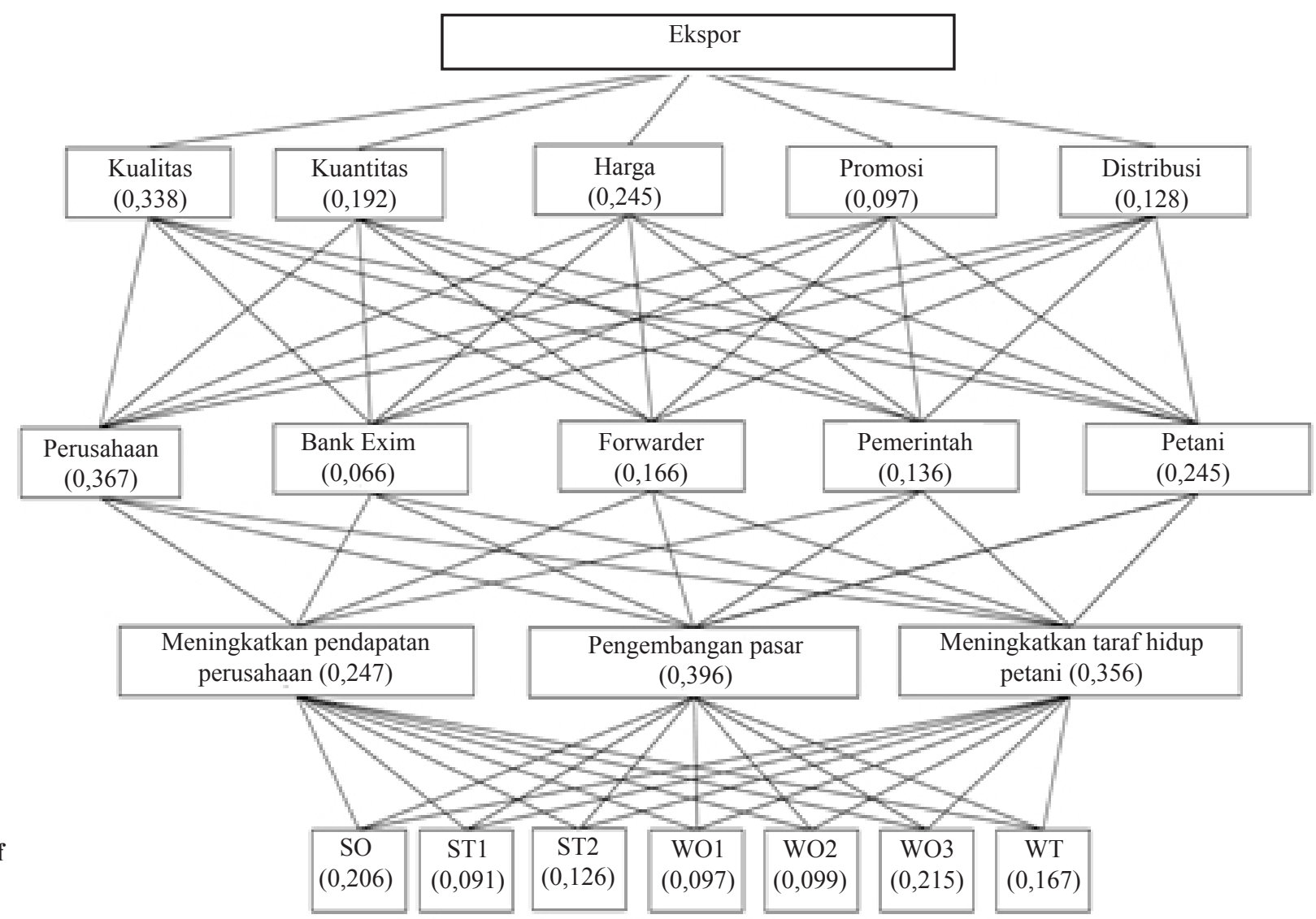

Alternatif Strategi

Tujuan

Gambar 3. Hasil pengolahan hierarki strategi pengembangan MTP 
Tabel 3. Hasil analisis dan prioritas setiap unsur hierarki

\begin{tabular}{clcc}
\hline \multicolumn{1}{c}{ Hierarki } & \multicolumn{1}{c}{ Unsur } & Skor & Prioritas \\
\hline Faktor & Kualitas & 0,338 & 1 \\
& Kuantitas & 0,192 & 3 \\
& Harga & 0,245 & 2 \\
& Promosi & 0,097 & 5 \\
\multirow{5}{*}{ Aktor } & Distribusi & 0,128 & 4 \\
& Perusahaan & 0,367 & 1 \\
& Bank Exim & 0,066 & 5 \\
& Forwarder & 0,166 & 3 \\
& Pemerintah & 0,136 & 4 \\
\multirow{5}{*}{ Tujuan } & Petani & 0,245 & 2 \\
& Meningkatkan pendapatan perusahaan & 0,247 & 3 \\
& Pengembangan pasar & 0,396 & 1 \\
& Meningkatkan taraf hidup petani & 0,356 & 2 \\
& SO & 0,206 & 2 \\
& ST1 & 0,091 & 7 \\
& ST2 & 0,126 & 4 \\
& WO1 & 0,097 & 6 \\
& WO2 & 0,099 & 5 \\
& WO3 & 0,215 & 1 \\
& WT & 0,167 & 3 \\
\hline
\end{tabular}

\section{Implikasi Manajerial}

Hasil penelitian yang dilakukan, pengembangan MTP dalam upaya menembus pasar ekspor membutuhkan serangakaian perbaikan dan persiapan demi tercapainya sasaran utama. Hasil analisis SWOT dan pengambilan keputusan dengan AHP, maka dapat dilihat altenatif strategi yang paling baik adalah menjalin kerja sama dengan agen forwarder dalam negeri. Ketersediaan informasi freight forwarder internasional dalam negeri yang banyak dengan masing-masing fasilitas pelayanan dapat diakses melalui media internet. Melalui kerja sama tersebut diharapkan MTP dapat memperoleh informasi yang lebih mendalam demi tercapainya sasaran utama dengan efektif dan efisien.

Mitra Tani Parahyangan (MTP) sebagai pelaku utama dalam proses pengembangan ini memiliki peran dan tanggung jawab yang besar dalam menghasilkan komoditas yang bermutu baik secara kualitas, kuantitas, dan harga. Hal ini dapat dicapai dengan melakukan perencanaan sistem tanam yang terstruktur di antara para mitra, peningkatan pengetahuan diantara para petani, dan adopsi teknologi dalam teknik budidaya.Tingginya penggunaan bahan pestisida kimia merupakan suatu faktor yang memiliki pengaruh terbesar dalam memengaruhi kualitas hasil akhir komoditas. Oleh karena itu, penerapan sistem pertanian semi organik merupakan suatu langkah awal yang dirasa perlu dalam rangka upaya meningkatkan daya saing komoditas yang dihasilkan. Hal tersebut dapat dilakukan dengan membuat standar kontrak kerja danperalihan penggunaan pestisida kimia ke pestisida organik.

\section{KESIMPULAN DAN SARAN}

\section{Kesimpulan}

Hasil analisis matriks IFE MTP memiliki total skor internal sebesar 2,379 yang menunjukkan bahwa posisi internal perusahaan saat ini lemah. Kekuatan utama MTP adalah penerapan GAP, GHP, dan GMP dalam proses produksi, dengan nilai skor sebesar 0,516. Sedangkan hal yang menjadi kelemahan utama adalah belum memiliki kontrak kerja sama yang tertulis dengan mitra, dengan nilai skor 0,118.Di sisi lain, hasil analisis matriks EFE memiliki nilai total skor sebesar 2,758, yang menunjukkan kemampuan perusahaan dalam mersepon faktor eksternal yang cukup baik dalam memanfaatkan peluang dan menghindari anacaman. Faktor ketersediaaan akses distribusi untuk ekspor di dalam negeri yang banyak merupakan peluang utama dengan nilai skor terbesar, yaitu 0,300. Sementara itu, faktor kondisi cuaca yang tidak menentu utama dengan nilai skor sebesar 0,337 merupakan faktor ancaman utama yang dihadapi MTP dalam upaya pengembangan untuk menembus pasar ekspor. 
Hasil perumusan alternatif strategi diperoleh tujuh strategi yang dapatditerapkan perusahaan. Rekomendasi strategi tersebut adalah membuat sertifikasi HACCP, membuat suatu kemasan produk yang memiliki nilai budaya lokal dan OVOP, pembelian lahan produksi dengan status kepemilikan, menerapakan sistem pertanian semi organik, menjalin kerja sama dengan agen forwarder dalam negeri, dan meningkatkan standar penanganan pasca panen

Prioritas strategi terpilih berdasarkan AHP adalah menjalin kerja sama dengan agen forwarder dalam negeri pada peringkat pertama, diikuti berturut-turut: memanfaatkan E-commerce sebagai media promosi perusahaan, meningkatkan standar penanganan pasca panen, membuat suatu kemasan produk yang memiliki nilai budaya lokal dan OVOP, memanfaatkan E-commerce sebagai media promosi perusahaan, menerapkan sistem pertanian semi organic, pembelian lahan produksi dengan status kepemilikan, dan membuat sertifikasi HACCP.

\section{Saran}

Peningkatan wawasan sumber daya manusia dan kontrol manajemen sangat diperlukan agar strategi yang dirumuskan dapat diterapkan dengan baik. Untuk penelitian lanjutan, diharapkan penelitian dapat dilakukan pada level fungsional yang dapat menghasilkan suatu kerangka kerja yang lebih efisien dan efektif.

\section{DAFTAR PUSTAKA}

Apulu I, Latham A. 2011. Driver for information and communication technology adoption: a case study of Nigerian small and medium sized enterprises. International Journal of Business and Management 6(5): 65-70. https://doi. org/10.5539/ijbm.v6n5p51.

Asikin Z.2016. Pengaruh infrastruktur dan kelembagaan terhadap kinerja ekspor agregat dan sektoral Indonesia. [Tesis]. Bogor: Institut Pertanian Bogor.

Chomchalow N, Songkhla PN. 2008. Thai mango export: a slow-but-sustainable development. Journal Technology 12(1): 1-8.

Chomchalow N, Somsri S, Songkhla PN. 2008. Marketing and export of major tropical fruits from Thailand. Assumption University Journal of Technology 11(3): 133-143.

Hill CWL, Wee CH, dan Udayasankar K. 2014. Bisnis Internasional: Perspektif Asia Buku 1. Jakarta: Salemba Empat

Islam GMN, Arshad FM, Radam A, dan Alias EF. 2012. Good agricultural practice (GAP) of tomatoes in Malaysia: evidence from Cameron Highlands. African Journal of Business Management 6(27):7969-7976.

[KEMENPERIN] Kementerian Perindustrian. 2017. Jaringan Dokumentasi dan Informasi Hukum. http://jdih.kemenperin.go.id/site/baca peraturan/113 [2017 Juli 29].

[KEMENTAN]. Kementerian Pertanian Republik Indonesia. 2014. Outlook Komoditi Tomat. http://pusdatin.setjen.pertanian.go.id. [2016 Agustus 20].

Kipdiyah S, Hubeis M, Suharjo B. 2013. Strategi rantai pasok sayuran organik berbasis petani di Kecamatan Pangalengan, Kabupaten Bandung. Jurnal Manajemen Pengembangan Industri Kecil Menengah 8(2) : 99-114

Kumar M, Agarwal A, Singh P, Singhal AK. 2017. Green packaging and marketing in promoting agribusiness. International Journal of Community Science and Technology 3(1): 17-24.

Kusnadi N, Tinaprilla N, Susilowati SH, dan Purwoto A. 2011. Analisis efisiensi usahatani padi di beberapa sentra produksi padi di Indonesia. Jurnal Agro Ekonomi 29(1) : 25-48. https://doi. org/10.21082/jae.v29n1.2011.25-48.

Kusuma RL, Firdaus M. 2015. Daya saing dan faktor yang memengaruhi volume ekspor sayuran Indonesia terhadap negara tujuan utama. Jurnal Manajemen dan Agribisnis 12(3):226-236

Miyauchi Y, Perry C. 1999. Marketing fresh fruit to Japanese consumers: exploring issues for Australian exporters. European Journal of Marketing 33(1/2): 196-205. https://doi. org/10.1108/03090569910249238.

Muafi, Titik K, Hendri G. 2010. Penguatan ekonomi lokal melalui e-readiness berbasis One Village One Product (OVOP). Jurnal Ekuitas 14(2):170 186. https://doi.org/10.24034/j25485024.y2010. v14.i2.2132.

Murphy PR, Daley JM. 2001. Profiling international freight forwarders: an update. International Journal of Physical Distribution and Logistics Management 31(3): 152-168. https://doi. org/10.1108/09600030110389433. 
Purnama IN. 2014. Strategi pemasaran mangga di Pasar Internasional [tesis]. Bogor: Institut Pertanian Bogor.

Rangkuti F. 2015. Analisis SWOT Teknik Membedah Kasus Bisnis. Jakarta: Gramedia Pustaka.

Schreinemachers P, Schad I, Tipraqsa P, Williams PM. 2012. Can public GAP standards reduce agricultural pesticide use? the case of fruit and vegetable farming in northern Thailand. Agriculture and Human Values 29(4):519-529. https://doi.org/10.1007/s10460-012-9378-6.

Sibarani M, Ispriyahadi H. 2004. Kerja Sama Perdagangan Internasional: Peluang dan Tantangan Bagi Indonesia. Jakarta: PT Alex Media Komputindo.

Srimanee Y, Routray JK. 2012. The fruit and vegetable marketing chains in Thailand: policy impacts and implications. International Journal of Retail \& Distribution Management 40(9): 656-675. https://doi.org/10.1108/09590551211255956.
Suharto CC. 2000. Peranan desain kemasan dalam dunia pemasaran. Jurnal Nirmana 2(1): 92-103.

Sutanto R. 2002. Penerapan Pertanian Organik Pemasyarakatan \& Pengembangannya. Yogyakarta: Kanisius.

Sutrisno A, Basith A, Wijaya NH. 2013. Analisis strategi penerapan sistem manajemen keamanan pangan HACCP (Hazard Analysis and Critical Control Points) di PT. Sierad Produce Tbk. Parung. Jurnal Manajemen dan Organisasi 4(2): 73-90. https://doi.org/10.29244/jmo.v4i2.12616.

Syachbanu D. 2014. Analisis penanganan kargo ekspor komoditas hortikultura di terminal kargo Bandara Internasional Soekarno Hatta: studi kasus PT Jasa Angkasa Semesta Tbk [tesis]. Bogor: Institut Pertanian Bogor.

Thaung NN. 2011. Integration of Myanmar domestic agricultural marketing into ASEAN. Journal of Management Policy and Practice 12(5):96-104. 